\title{
The dose of inhaled corticosteroids in patients with COPD: when less is better
}

This article was published in the following Dove Press journal: International Journal of COPD

José Luis Izquierdo' Borja G Cosio 2,3

'Department of Pneumology and Medicine, Hospital Universitario, Universidad de Alcalá, Guadalajara, Spain; ${ }^{2}$ Department of Respiratory Medicine, Hospital Son Espases-IdISBa, Palma de Mallorca, Spain; ${ }^{3}$ CIBER de Enfermedades Respiratorias (CIBERES), Instituto de Salud Carlos III, Madrid, Spain
Correspondence: José Luis Izquierdo Department of Pneumology and Medicine, Hospital Universitario de Guadalajara, C/Donante de Sangre S/N, 19002 Guadalajara, Spain

Tel +34 655946652

Email jlizquierdoa@gmail.com
Background: The use of inhaled corticosteroids (ICS) in combination with bronchodilators in patients with COPD has been shown to decrease the rate of disease exacerbations and to improve the lung function and patients' quality of life. However, their use has also been associated with an increased risk of pneumonia.

Materials and methods: We have reviewed existing clinical evidence on the risks and benefits of ICS in COPD, including large randomized clinical trials, meta-analyses, and clinical reviews.

Results: A large body of evidence supports the clinical benefits of ICS in patients with COPD in terms of exacerbations, symptoms, lung function, and quality of life. The incidence of adverse events related to ICS, including pneumonia, varies strongly among the studies and seems to be dose dependent, with recent well-designed, large studies on low-dose ICS reporting similar safety profiles in ICS and non-ICS groups.

Conclusion: The benefits of ICS in COPD continue to outweigh the risks, especially when lower ICS doses are employed. Given that the data on ICS withdrawal in COPD are scarce and conflicting, we argue that using reduced doses of ICS could be an optimal strategy to manage patients with COPD.

Keywords: acute exacerbations, anti-inflammatory effects, COPD, asthma-COPD overlap syndrome, inhaled corticosteroids, lower doses of ICS, pneumonia

\section{Introduction}

A high and growing prevalence of COPD has been reported both globally and regionally. According to the estimations of Burden of Obstructive Lung Disease program and other epidemiological studies, the number of patients with COPD in 2010 was around 384 million worldwide. ${ }^{1}$ Globally, there are around 3 million COPD-related deaths annually, with an increase in the prevalence of smoking, and of indoor air pollution from biomass cooking and heating in developing countries. This fact, and increased aged population in developed countries, led the WHO to estimate that the prevalence of COPD would increase over the next years, so that by 2030, there may be about 4.5 million deaths per year from this disease. ${ }^{2}$ Despite recent trends in reduction of COPD standardized mortality rates and some success in anti-smoking efforts in developed countries, the overarching demographic impact of aging in an ever-expanding world population, combined with other factors such as high rates of smoking and air pollution ensure that COPD will continue to represent an ever-increasing problem in the 21 st century. ${ }^{3}$

These overwhelming epidemiological data of COPD pose a huge challenge for clinicians, health care systems, and societies. Much of the burden of COPD is due to exacerbations, which are associated with increased disease progression, 
reduced quality of life, and increased costs, especially those related to hospitalization. ${ }^{4,5}$ The most recent strategy document from the GOLD advocates for a reduction of the risk of exacerbations as the central part of the pharmacological therapy for any patient with COPD. ${ }^{6}$ Goals of effective COPD management, including symptom relief, prevention of exacerbations and disease progression, improvement of health status, reduction of mortality, improved exercise tolerance, and prevention and treatment of complications should be reached at the cost of minimal side effects from treatment. ${ }^{7-9}$

However, despite the existence of effective pharmacological treatments, management in daily practice can be complex for different reasons. COPD is a heterogeneous chronic entity, patients often suffer from comorbidities, and long-term treatment is frequently required, which may increase the risk of adverse events and raise concerns about adherence to prescribed medications. ${ }^{10}$ At the same time, some subgroups of patients with COPD, such as those with greater lung function impairment, are highly susceptible to recurrent exacerbations that increase the severity of their condition. ${ }^{11-14}$

Treatment of patients with COPD in daily practice continues to pose challenges for physicians to achieve the maximum benefit of non-pharmacological measures (eg, smoking cessation and rehabilitation) and pharmacological treatments (eg, bronchodilators and inhaled corticosteroids [ICS]) in the individual patient. All these options are relevant and effective. However, the usefulness of ICS in COPD has been questioned lately because of concerns about potential side effects such as pneumonia. Importantly, high doses of ICS are commonly prescribed to COPD patients, with trials involving doses of $1,000 \mu \mathrm{g}$ fluticasone propionate per day during 2-3 years, ${ }^{15,16}$ whereas it is becoming increasingly clear that most ICS adverse reactions are dose related, and using lower doses of ICS substantially reduces the risk of undesired effects. ${ }^{17}$ Therefore, it is a convenient time for revising the role of ICS in the management of COPD based on the recent clinical data of efficacy, safety, underlying physiopathology mechanisms, and dose-response effects, all of which affect the benefit-risk balance of ICS. To this purpose, a comprehensive review of MEDLINE/PubMed and the Cochrane Library databases was made. Search MeSH terms included "chronic obstructive pulmonary disease", "bronchodilator agents", "administration/inhalation", "glucocorticoids", "beta-adrenergic antagonists", "muscarinic antagonists", "pneumonia", and "quality of life". References of retrieved articles were cross-checked for additional studies.

\section{Efficacy of ICS in the management of patients with COPD}

A number of randomized controlled clinical trials have provided evidence of the higher efficacy of ICS combined with a long-acting beta ${ }_{2}$-adrenoreceptor agonist (LABA) compared to placebo in reducing exacerbations (between $24 \%$ and $41 \%$ ) and improving the lung function (mean change in $\mathrm{FEV}_{1}$ between 92 and $144 \mathrm{~mL}$ ) and quality of life (mean difference in scores of the St George's Respiratory Questionnaire [SGRQ] between 2.4 and 7.5). ${ }^{18-20}$

Combinations of ICS/LABA also significantly reduced the yearly rate of moderate and severe exacerbations (between $25 \%$ and $30 \%$ ) and improved the lung function and quality of life as measured by SGRQ score, when compared with LABA alone, ${ }^{19,21-25}$ particularly in patients with frequent exacerbations. ${ }^{26-28}$ The beneficial effects of combining ICS with LABA have also been confirmed in systematic reviews and metaanalyses. ${ }^{29,30}$ Although in the Towards a Revolution in COPD Health study, the difference between an ICS/LABA combination and LABA alone in all-cause mortality was not statistically significant $(P=0.052),{ }^{15}$ several observational studies showed that the use of ICS/LABA combination was associated with a reduced total mortality, compared with LABA monotherapy. ${ }^{22,31}$

The beneficial effect of ICS in COPD patients is stronger for those with a concurrent asthma diagnosis or with a history of exacerbations. It has been estimated that the prevalence of asthma-COPD overlap syndrome among COPD patients is around $20 \%$, and that these patients have a better prognosis when treated with ICS/LABA. ${ }^{32,33}$

\section{Safety of ICS in the management of patients with COPD \\ Pneumonia}

The impact of ICS use on the development of pneumonia has been heavily debated. An increased incidence of pneumonia associated with ICS was observed in several clinical trials including Towards a Revolution in COPD Health ${ }^{25}$ and the Investigating New Standards for Prophylaxis in Reducing Exacerbations studies. ${ }^{16}$ It should be noted, however, that the protocols of these trials lacked the prospective definition of pneumonia (eg, confirmation by chest radiography), which might potentially lead to overdiagnosis of pneumonia. Other studies demonstrated no increased risk for pneumonia and no effects of ICS on pneumonia-related mortality. ${ }^{20,34,35}$ Systematic reviews and meta-analyses also provided conflicting results. ${ }^{36,37}$ Interestingly, the incidence of pneumonia reported in the most recent clinical trials on patients with COPD has decreased, which could be related to the usage of lower doses of ICS in 


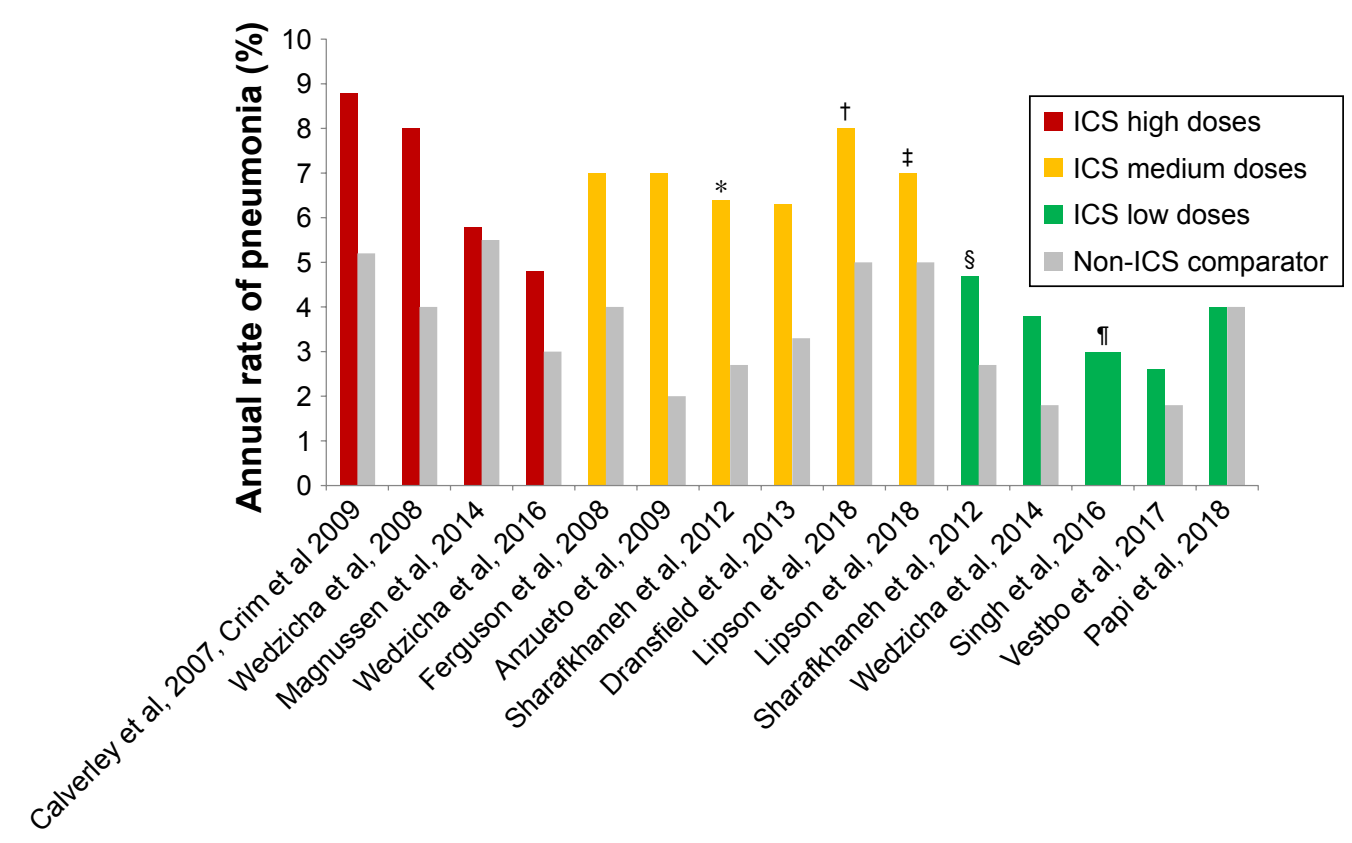

Figure I Incidence rates of pneumonia in different studies according to doses of ICS.

Notes: *Comparison between beclometasone/formoterol $640 / 18 \mu \mathrm{g}$ formoterol $18 \mu \mathrm{g} .{ }^{\dagger}$ Comparison between fluticasone furoate/umeclidinium/vilanterol vs umeclidinium/ vilanterol. ${ }^{\ddagger}$ Comparison between $\mathrm{FF} /$ vilanterol vs umeclidinium/vilanterol. ${ }^{\circledR}$ Comparison between beclometasone/formoterol $320 / I 8 \mu \mathrm{g}$ formoterol I8 $\mu \mathrm{g}$. "Both arms of the study were treated with ICS (extrafine BDP/FF/G 400/24/50 vs extrafine BDP/FF 400/24). Only ICS doses approved in COPD are considered.

Abbreviations: BDP, beclomethasone dipropionate; FF, fluticasone furoate; G, glycopyrronium; ICS, inhaled corticosteroids.

the treatment regimens (Figure 1). Thus, data from the recent TRINITY study, in which low doses of ICS were used in a fixed combination with a long-acting muscarinic antagonist and a LABA, showed that the incidence of pneumonia and of other adverse events was similar between the triple regimen and long-acting muscarinic antagonist monotherapy. ${ }^{38}$

Concordantly, there is a consistent evidence of a doseresponse effect for the link between ICS and pneumonia coming from observational studies. In a population-based cohort study of 163,514 patients with COPD treated with inhaled medications between 1990 and 2005 in the province of Quèbec, Canada, there were 20,344 patients who were identified as having had at least one episode of pneumonia. ${ }^{39}$ After adjusting for differences in covariates in cases and controls, current use of ICS was associated with an increase in the rate ratio (RR) of pneumonia of 1.69 , which was dose dependent, ranging from an RR of 1.24 for the lower doses to an RR of 1.86 with the highest doses of ICS (equivalent to fluticasone propionate $1,000 \mu \mathrm{g} /$ day or more). Also, in a nested case-control study, the risk of hospitalization for pneumonia increased with ICS dose: while the RR for current use of ICS (all doses) was 1.70, the RR for the highest dose of ICS (equivalent to fluticasone propionate $1,000 \mu \mathrm{g} /$ day or more) was as high as 2.25. ${ }^{40} \mathrm{~A}$ higher ICS dosage has been found to correlate significantly with a higher load of typical airway bacteria in COPD patients ${ }^{41}$ and with an increased risk of Mycobacterium tuberculosis infection. ${ }^{42}$ In a recent retrospective analysis of 23,013 patients with obstructive lung disease in the UK, patients receiving daily ICS doses in excess of $700 \mu \mathrm{g}$ (fluticasone propionate equivalent) were significantly more likely (OR 2.38, 95\% CI: 1.17-4.83; $P=0.001)$ to have pneumonia compared with patients who were prescribed lower doses. Furthermore, irrespective of the dose, patients with extrafine particles of ICS (particles with a mass median aerodynamic diameter of $1.1 \mu \mathrm{m}$ ) were at a lower risk of pneumonia (adjusted OR 0.60, 95\% CI: $0.37-0.97 ; P=0.011$ ) and acute exacerbations (adjusted RR $0.91,95 \%$ CI: $0.85-0.97 ; P=0.001)$ compared with those with ICS of larger particle size distribution profiles. ${ }^{43}$

\section{Systemic adverse effects}

Prolonged use of ICS can cause systemic adverse effects. Systemic adverse effects related to the use of ICS in COPD have been addressed in a comprehensive systematic review and meta-analysis. ${ }^{44}$ For most studied systemic adverse events, such as adrenal axis suppression, osteoporosis, and diabetes, a dose-dependent relationship was observed and is suggested to be limited by the partial systemic ICS absorption at high doses. ${ }^{42,44-48}$

\section{Benefit-risk balance of ICS}

When assessing the benefit-risk balance of a treatment, it is important to take into account both the seriousness of the alleviated conditions and of the side effects and their 
incidence. In COPD, moderate-to-severe exacerbations have been linked to disease progression, increased risk of further exacerbations, faster decline of pulmonary function, and higher risk of mortality. ${ }^{49-51}$ Interestingly, there has been no increase of pneumonia-related mortality in patients treated with ICS in clinical trials. ${ }^{52}$ As for the incidence, COPD exacerbations are much more frequent events than pneumonia, with $>40 \%$ of patients reported to suffer moderate-to-severe exacerbations of COPD in clinical trials and the annual rates frequently surpassing one such exacerbation per patient per year, whereas only $2 \%-7 \%$ of patients experience pneumonia (Table 1).

Regarding the benefit-risk of the ICS dosage, two recently published studies have provided important information. In a randomized trial (IMPACT study) ${ }^{53}$ involving 10,355 patients with COPD, 52 weeks of a once-daily fixed-dose combination of fluticasone furoate $100 \mu \mathrm{g}$, umeclidinium $62.5 \mu \mathrm{g}$, and vilanterol of $25 \mu \mathrm{g}$ was compared with fluticasone furoate-vilanterol 100/25 $\mu \mathrm{g}$ and umeclidiniumvilanterol $100 / 62.5 \mu \mathrm{g}$. The dose of fluticasone furoate in the triple therapy could be comparable to $500 \mu \mathrm{g}$ of fluticasone propionate and, therefore, considered a medium ICS dose. After 52 weeks of treatment, it was found that fluticasone furoate/umeclidinium/vilanterol significantly reduced the rate of moderate-to-severe exacerbations compared with furoate/vilanterol and umeclidinium/vilanterol, with an small increase in the incidence of total pneumonias in the arms with ICS vs the arms without ICS, $8 \%$ and $7 \%$ for the triple therapy and fluticasone furoate/vilanterol, respectively, vs $5 \%$ for umeclidinium/vilanterol.

The other recent randomized study in COPD was the TRIBUTE study, ${ }^{54}$ in which an extrafine triple fixed combination of beclometasone, formoterol, and glycopyrronium $(87 / 5 / 9 \mu \mathrm{g})$ twice daily was compared with a dual bronchodilator therapy of indacaterol plus glycopyrronium $(85 / 43)$ in 1,532 patients with COPD. The dose of beclometasone in the extrafine triple therapy is considered a low ICS dose. After 52 weeks of treatment, it was found that extrafine beclometasone/formoterol/glycopyrronium significantly reduced the rate of moderate-to-severe exacerbations compared with indacaterol/glycopyrronium, without increasing the risk of pneumonia (incidence of pneumonia $4 \%$ in the two study groups).

Also, a recent assessment report of the European Medicines Agency of the risk of pneumonia in COPD patients treated with ICS concluded that the benefit-risk balance of ICS-containing products remained favorable, despite the increased risk of pneumonia associated with the ICS. ${ }^{45}$
The report also emphasized that pneumonia was an intrinsic comorbidity to COPD in the presence of certain predisposing factors, and stressed the difficulties of the differential diagnosis of pneumonia and COPD exacerbations. The assessment concluded that the concept of a dose-response for the pneumonia risk had biological plausibility and should be counted as supportive clinical evidence.

\section{Pathophysiological mechanisms of the benefit-risk balance of ICS}

The dose-response curve for clinical response to ICS is relatively flat, in contrast to the steeper dose-response curve for ICS-related adverse effects (Figure 2). ${ }^{55,56}$ This implies that increasing the dose of ICS on the flat part of the efficacy curve may confer little additional benefit, but at the same time may considerably increase the chance of adverse effects, resulting in a worse clinical index. ${ }^{56-58}$ Of note, fluticasone propionate has the highest level of lipophilicity among ICS and prolonged systemic tissue retention, which, combined with high potency and affinity toward the glucocorticoid receptor, may explain in part its greater systemic activity compared with other available ICS. Indeed, high doses of inhaled fluticasone propionate have been associated with the greatest dose-related systemic bioactivity. ${ }^{55}$

Optimizing the ICS dosage and minimizing the risk of adverse effects are especially relevant for patients with COPD, since they tend to be older and to have several comorbid conditions for which they are frequently multidrug users. All of these make them particularly susceptible to potential adverse effects of high-dose ICS treatment. ${ }^{59}$

A favorable risk-benefit ratio of using lower doses of ICS while maintaining clinical efficacy is also supported by a growing trend differentiating between the predominantly immunosuppressive effects of high doses of ICS vs the predominantly anti-inflammatory effects of lower doses. ${ }^{45,60-62}$ It has been shown that ICS have the potential to modify cellular and humoral pathways of the immune networks of the lung that are required in normal conditions for efficient clearance of pathogens such as pneumococci. ${ }^{60}$ The potential of high doses of ICS to inhibit the cellular components of the immune response involving alveolar macrophages, T-cells, and other signaling cytokines has been postulated based on the observed increased airway bacterial load and increased risk of mycobacterial infections, including cases of reactivation of pulmonary tuberculosis. ${ }^{39,41,42,59,60,63}$ By contrast, lower doses of ICS seem to exhibit predominantly antiinflammatory effects with modulation of the humoral components of the innate immune response, which may lead to 


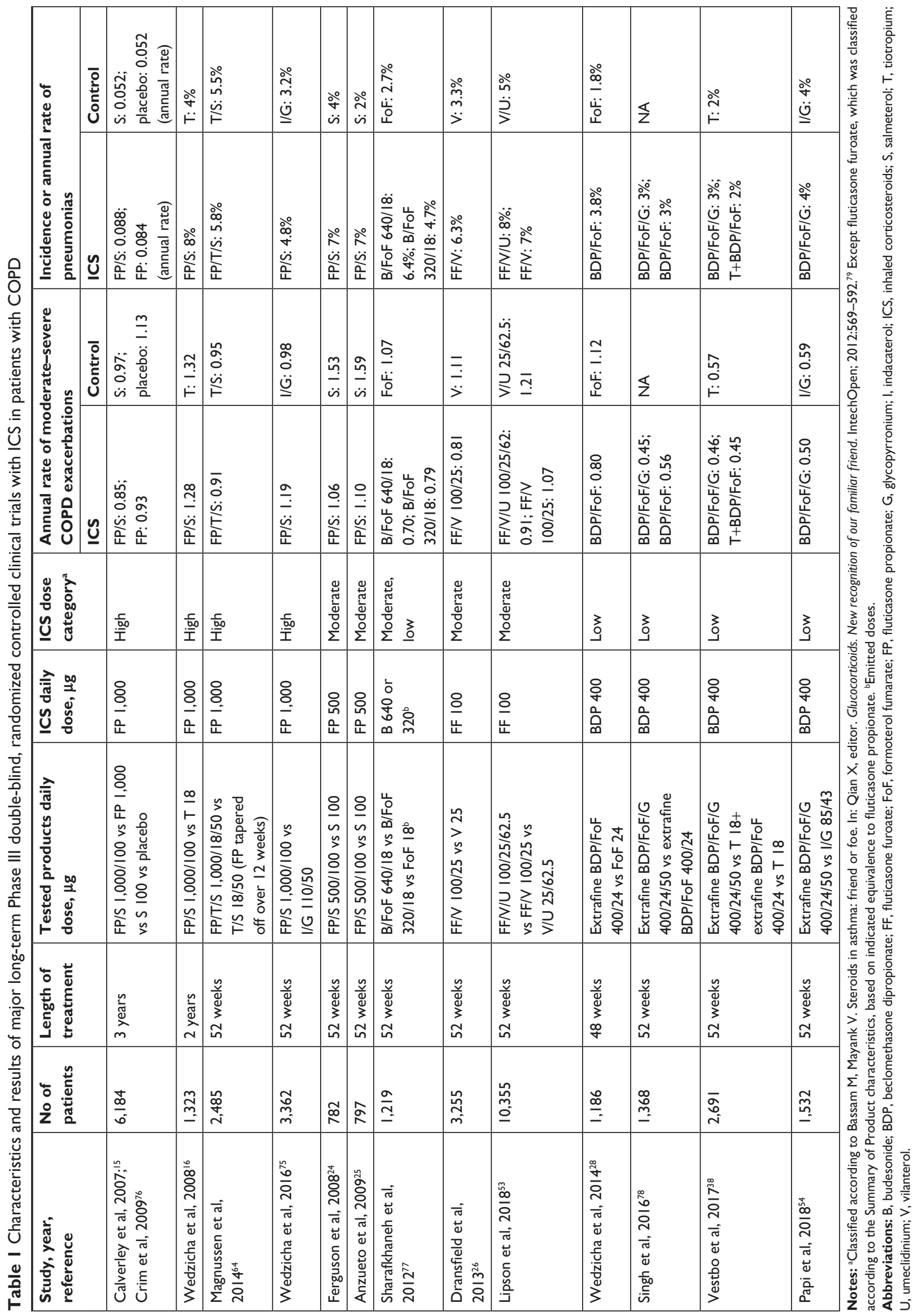




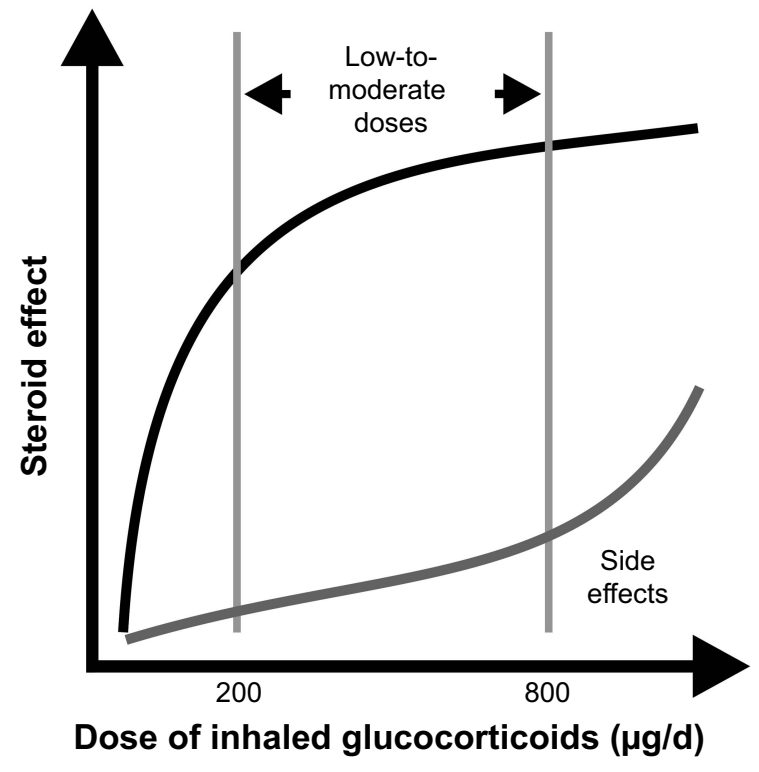

Figure 2 The dose-response curve of ICS.

Note: Reproduced from Kankaanranta et al, 2004,56 with the permission of Respiratory Research.

Abbreviation: ICS, inhaled corticosteroids.

reduced airway bacterial load and reduced risk of pneumonia and tuberculosis. ${ }^{42,61}$ The mechanisms involved in systemic adverse effects of ICS are summarized in Figure 3. Taken into consideration the predominantly anti-inflammatory effects as well as low systemic exposure associated with lower ICS doses, the ICS dose reduction (rather than withdrawal) would be a plausible therapeutic option for many COPD patients.

\section{Effects of ICS withdrawal}

The effect of ICS withdrawal on lung function, symptoms, and exacerbations remains unclear, since the studies published so far have provided conflicting results. ${ }^{64-68}$ Some studies have shown an increase in exacerbations and/or worsening of symptoms following ICS withdrawal, while others have not. A recent study conducted in 2,485 patients with moderate COPD has found no change in the incidence of exacerbations after ICS discontinuation, but a significant worsening in $\mathrm{FEV}_{1}$ and quality of life was observed, instead. ${ }^{64}$ Moreover, more detailed analysis from this study showed a significant increase in the incidence of severe exacerbations after ICS withdrawal and a heterogeneous response, ${ }^{69}$ with a significant increase of exacerbations in those with blood eosinophil counts of $\geq 4 \%$ or $\geq 300$ cells $/ \mu$ L. ${ }^{70}$ Interestingly, although ICS in this study were discontinued gradually in three steps over a 12-week period, the worsening in $\mathrm{FEV}_{1}$ became apparent only at the point of complete ICS withdrawal. ${ }^{71}$ This observation supports the hypothesis that using lower doses of ICS in COPD could be a better choice than their complete discontinuation. Intriguingly, there were no differences between the two arms in terms of pneumonia incidence, suggesting that ICS use was not associated with an increased pneumonia risk. ${ }^{72}$

Another recent study has provided data on withdrawal of ICS in patients on long-term triple therapy in the absence of frequent exacerbations. ${ }^{73}$ This 26 -week, randomized, doubleblind, triple-dummy study (SUNSET study) assessed the direct change from long-term triple therapy to indacaterol/ glycopyrronium $(110 / 50 \mu \mathrm{g}$ once daily) or continuation of triple therapy (tiotropium [18 $\mu \mathrm{g}]$ once daily plus combination of salmeterol/fluticasone propionate [50/500 $\mu \mathrm{g}]$ twice daily). Primary endpoint was noninferiority on change from baseline in trough $\mathrm{FEV}_{1}$. ICS withdrawal led to a reduction in
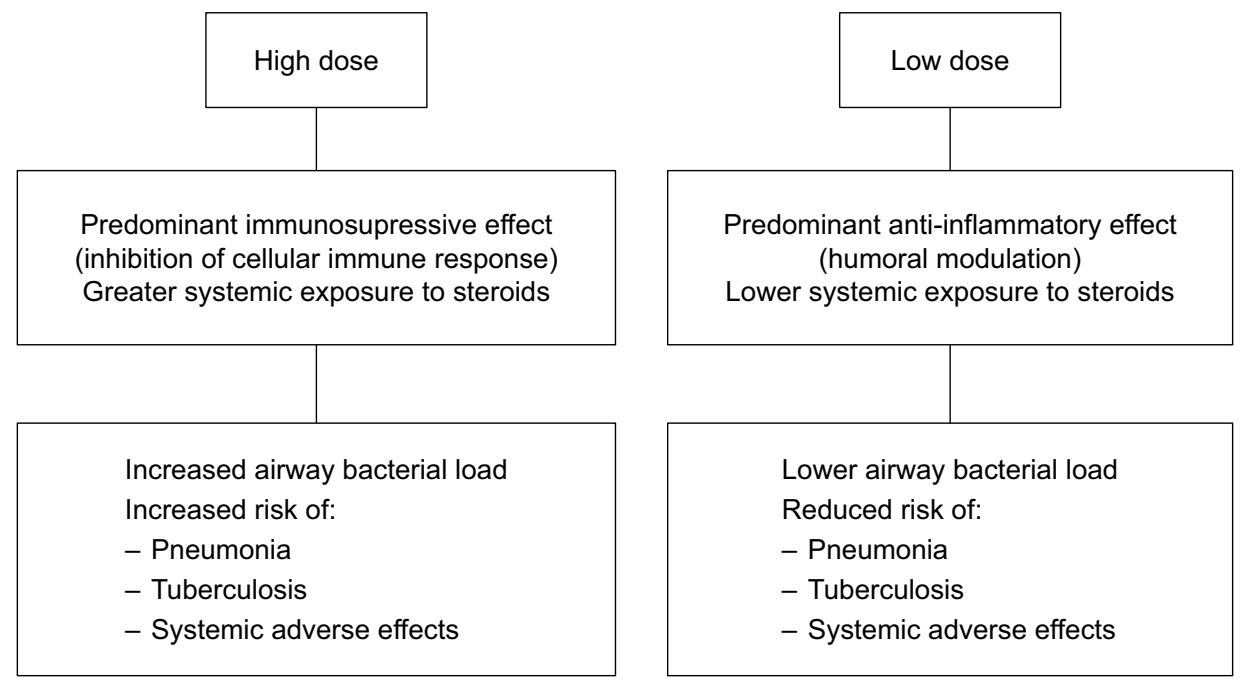

Figure 3 Pathophysiological mechanisms involved in systemic adverse effects of ICS in COPD patients. Abbreviation: ICS, inhaled corticosteroids. 
trough $\mathrm{FEV}_{1}$ of $-26 \mathrm{~mL}$ (95\% CI: $\left.-53,1 \mathrm{~mL}\right)$ with confidence limits exceeding the noninferiority margin of $-50 \mathrm{~mL}$. Differences in COPD exacerbations were not observed, although 26 weeks is not a sufficient time to assess differences in terms of exacerbations. Patients with $\geq 300$ blood eosinophils $/ \mu \mathrm{L}$ at baseline presented greater lung function loss and higher exacerbation risk, which suggests that these patients may obtain more benefit from triple therapy. Also, differences in quality of life (total score of the SGRQ) in favor of triple therapy were observed.

Finally, a post hoc pooled analysis of three randomized controlled trials of budesonide-formoterol in patients with COPD with a history of exacerbations and available blood eosinophil counts (INCONTROL study) ${ }^{74}$ showed nonlinear increase in exacerbations occurred with increasing eosinophil count in patients who received formoterol alone. Budesonide-formoterol compared with formoterol alone reduced the risk of exacerbation by $68 \%$ in patients with eosinophil count $\geq 0.6 \times 10^{9} / \mathrm{L}$. By contrast, in ex-smokers, budesonide-formoterol reduced the risk of exacerbations in only 34\%-39\% vs formoterol alone. The effect of treatment in ex-smokers was independent of the eosinophil count. These results suggest that in COPD patients who are active smokers, the eosinophil count may be a strong and independent predictor of future exacerbations.

\section{Concluding remarks}

Inhaled steroids in combination with long-acting bronchodilators have become a standard treatment strategy for COPD, especially in patients suffering from frequent exacerbations and in those with mixed asthma-COPD phenotype. Increased risk of pneumonia and systemic adverse effects of ICS have generated a debate around their long-term use, in particular, for high doses of ICS. The safety profile of ICS seems to be dose dependent and most serious adverse events have been related to the use of high doses (eg, fluticasone propionate $1,000 \mu \mathrm{g} /$ day), with a reduced risk when lower doses are given. The relatively flat dose-response curve explains the little clinical benefit derived from increasing ICS dose above minimally effective doses, whereas the risk of adverse events is increased, coinciding with the steeper part of the dose-response curve for systemic effects. Also, differences in physiopathological mechanisms underlying the action of ICS, predominantly immunosuppressive at high doses and anti-inflammatory at lower doses, further support the strategy of using lower ICS doses. These considerations highlight the value of using low-dose ICS in the management of COPD.

\section{Acknowledgment}

The authors thank Marta Pulido, MD, PhD, for editing the manuscript and editorial assistance.

\section{Disclosure}

José Luis Izquierdo reports speaker fees, travel grants, and advisory board fees from AstraZeneca, Bayer, BoehringerIngelheim, Chiesi, Glaxo Smith Kline, Menarini, Novartis, Pfizer, Sandoz, and Teva. Borja G. Cosio reports speaker fees, travel grants, and advisory board fees from AstraZeneca, Boehringer-Ingelheim, Chiesi, Menarini, Mundipharma, Novartis, Sanofi, and Teva.

\section{References}

1. Adeloye D, Chua S, Lee C, et al. Global and regional estimates of COPD prevalence: Systematic review and meta-analysis. J Glob Health. 2015;5(2):020415.

2. World Health Organization. Projections of mortality and causes of death, 2015 and 2030. Available from: http://www.who.int/healthinfo/global burden disease/projections/en/. Accessed September 25, 2017.

3. López-Campos JL, Tan W, Soriano JB. Global burden of COPD. Respirology. 2016;21(1):14-23.

4. Halpin DM, Decramer M, Celli B, Kesten S, Liu D, Tashkin DP. Exacerbation frequency and course of COPD. Int J Chron Obstruct Pulmon Dis. 2012;7:653-661.

5. Aaron SD. Management and prevention of exacerbations of COPD. BMJ. 2014;349:g5237.

6. Global Initiative for Chronic Obstructive Lung Disease. Pocket guide to COPD diagnosis, management, and prevention. A Guide for health care professionals 2017. Available from: http://goldcopd.org/wp-content/ uploads/2016/12/wms-GOLD-2017-Pocket-Guide.pdf. Accessed May 3, 2017.

7. Vestbo J, Lange P. Prevention of COPD exacerbations: medications and other controversies. ERJ Open Res. 2015;1(1):00011.

8. Montuschi P. Pharmacological treatment of chronic obstructive pulmonary disease. Int J Chron Obstruct Pulmon Dis. 2006;1(4):409-423.

9. Spencer P, Hanania NA. Optimizing safety of COPD treatments: role of the nurse practitioner. J Multidiscip Healthc. 2013;6:53-63.

10. Bourbeau J, Bartlett SJ. Patient adherence in COPD. Thorax. 2008; 63(9):831-838.

11. Restrepo RD, Alvarez MT, Wittnebel LD, et al. Medication adherence issues in patients treated for COPD. Int J Chron Obstruct Pulmon Dis. 2008;3(3):371-384.

12. Decramer M, Janssens W, Miravitlles M. Chronic obstructive pulmonary disease. Lancet. 2012;379(9823):1341-1351.

13. Hurst JR, Vestbo J, Anzueto A, et al. Susceptibility to exacerbation in chronic obstructive pulmonary disease. $N$ Engl J Med. 2010;363(12): $1128-1138$.

14. Miravitlles M, Calle M, Soler-Cataluña JJ. Clinical phenotypes of COPD: identification, definition and implications for guidelines. Arch Bronconeumol. 2012;48(3):86-98.

15. Calverley PM, Anderson JA, Celli B, et al. Salmeterol and fluticasone propionate and survival in chronic obstructive pulmonary disease. N Engl J Med. 2007;356(8):775-789.

16. Wedzicha JA, Calverley PM, Seemungal TA, et al. The prevention of chronic obstructive pulmonary disease exacerbations by salmeterol/ fluticasone propionate or tiotropium bromide. Am J Respir Crit Care Med. 2008;177(1):19-26.

17. Pandya D, Puttanna A, Balagopal V. Systemic effects of inhaled corticosteroids: an overview. Open Respir Med J. 2014;8:59-65. 
18. Szafranski W, Cukier A, Ramirez A, et al. Efficacy and safety of budesonide/formoterol in the management of chronic obstructive pulmonary disease. Eur Respir J. 2003;21(1):74-81.

19. Calverley PM, Boonsawat W, Cseke Z, Zhong N, Peterson S, Olsson H. Maintenance therapy with budesonide and formoterol in chronic obstructive pulmonary disease. Eur Respir J. 2003;22(6):912-919.

20. Rennard SI, Tashkin DP, Mcelhattan J, et al. Efficacy and tolerability of budesonide/formoterol in one hydrofluoroalkane pressurized metereddose inhaler in patients with chronic obstructive pulmonary disease: results from a 1-year randomized controlled clinical trial. Drugs. 2009; 69(5):549-565.

21. Calverley P, Pauwels R, Vestbo J, et al. Combined salmeterol and fluticasone in the treatment of chronic obstructive pulmonary disease: a randomised controlled trial. Lancet. 2003;361(9356):449-456.

22. Gershon AS, Campitelli MA, Croxford R, et al. Combination longacting $\beta$-agonists and inhaled corticosteroids compared with long-acting $\beta$-agonists alone in older adults with chronic obstructive pulmonary disease. JAMA. 2014;312(11):1114-1121.

23. Hanania NA, Darken P, Horstman D, et al. The efficacy and safety of fluticasone propionate $(250 \mathrm{microg}) /$ salmeterol (50 microg) combined in the Diskus inhaler for the treatment of COPD. Chest. 2003;124(3): 834-843.

24. Ferguson GT, Anzueto A, Fei R, Emmett A, Knobil K, Kalberg C. Effect of fluticasone propionate/salmeterol (250/50 microg) or salmeterol (50 microg) on COPD exacerbations. Respir Med. 2008;102(8): 1099-1108.

25. Anzueto A, Ferguson GT, Feldman G, et al. Effect of fluticasone propionate/salmeterol $(250 / 50)$ on COPD exacerbations and impact on patient outcomes. COPD. 2009;6(5):320-329.

26. Dransfield MT, Bourbeau J, Jones PW, et al. Once-daily inhaled fluticasone furoate and vilanterol versus vilanterol only for prevention of exacerbations of COPD: two replicate double-blind, parallel-group, randomised controlled trials. Lancet Respir Med. 2013;1(3):210-223.

27. Kardos P, Wencker M, Glaab T, Vogelmeier C. Impact of salmeterol/ fluticasone propionate versus salmeterol on exacerbations in severe chronic obstructive pulmonary disease. Am J Respir Crit Care Med. 2007;175(2):144-149.

28. Wedzicha JA, Singh D, Vestbo J, et al. Extrafine beclomethasone/ formoterol in severe COPD patients with history of exacerbations. Respir Med. 2014;108(8):1153-1162.

29. Kew KM, Dias S, Cates CJ. Long-acting inhaled therapy (beta-agonists, anticholinergics and steroids) for COPD: a network meta-analysis. Cochrane Database Syst Rev. 2014;3(3):CD010844.

30. Nannini LJ, Cates CJ, Lasserson TJ, Poole P. Combined corticosteroid and long-acting beta-agonist in one inhaler versus long-acting betaagonists for chronic obstructive pulmonary disease. Cochrane Database Syst Rev. 2007;4:CD006829.

31. di Martino M, Agabiti N, Cascini S, et al. The effect on total mortality of adding inhaled corticosteroids to long-acting bronchodilators for COPD: a real practice analysis in Italy. COPD. 2016;13(3):293-302.

32. Cosio BG, Soriano JB, López-Campos JL, et al. Defining the asthmaCOPD overlap syndrome in a COPD cohort. Chest. 2016;149(1): 45-52.

33. Suzuki M, Makita H, Konno S, et al. Asthma-like features and clinical course of chronic obstructive pulmonary disease. An analysis from the Hokkaido COPD Cohort Study. Am JRespir Crit Care Med.2016;194(11): 1358-1365.

34. Tashkin DP, Rennard SI, Martin P, et al. Efficacy and safety of budesonide and formoterol in one pressurized metered-dose inhaler in patients with moderate to very severe chronic obstructive pulmonary disease: results of a 6-month randomized clinical trial. Drugs. 2008;68(14): 1975-2000.

35. Welte T, Miravitlles M, Hernandez P, et al. Efficacy and tolerability of budesonide/formoterol added to tiotropium in patients with chronic obstructive pulmonary disease. Am J Respir Crit Care Med. 2009;180(8): $741-750$.
36. Kew KM, Seniukovich A. Inhaled steroids and risk of pneumonia for chronic obstructive pulmonary disease. Cochrane Database Syst Rev. 2014;3:CD010115.

37. Sin DD, Tashkin D, Zhang X, et al. Budesonide and the risk of pneumonia: a meta-analysis of individual patient data. Lancet. 2009; 374(9691):712-719.

38. Vestbo J, Papi A, Corradi M, et al. Single inhaler extrafine triple therapy versus long-acting muscarinic antagonist therapy for chronic obstructive pulmonary disease (TRINITY): a double-blind, parallel group, randomised controlled trial. Lancet. 2017;389(10082):1919-1929.

39. Suissa S, Patenaude V, Lapi F, Ernst P. Inhaled corticosteroids in COPD and the risk of serious pneumonia. Thorax. 2013;68(11):1029-1036.

40. Ernst P, Gonzalez AV, Brassard P, Suissa S. Inhaled corticosteroid use in chronic obstructive pulmonary disease and the risk of hospitalization for pneumonia. Am J Respir Crit Care Med. 2007;176(2):162-166.

41. Garcha DS, Thurston SJ, Patel AR, et al. Changes in prevalence and load of airway bacteria using quantitative PCR in stable and exacerbated COPD. Thorax. 2012;67(12):1075-1080.

42. Brassard P, Suissa S, Kezouh A, Ernst P. Inhaled corticosteroids and risk of tuberculosis in patients with respiratory diseases. Am J Respir Crit Care Med. 2011;183(5):675-678.

43. Sonnappa S, Martin R, Israel E, et al. Risk of pneumonia in obstructive lung disease: a real-life study comparing extra-fine and fine-particle inhaled corticosteroids. PLoS One. 2017;12(6):e0178112.

44. Lipworth BJ. Systemic adverse effects of inhaled corticosteroid therapy: a systematic review and meta-analysis. Arch Intern Med. 1999; 159(9):941-955.

45. European Medicines Agency. Assessment report EMA/330021/2016. Inhaled corticosteroids (ICS) containing medical products indicated in the treatment of chronic obstructive pulmonary disease (COPD). London, UK; European Medicines Agency; 2016.

46. Loke YK, Cavallazzi R, Singh S. Risk of fractures with inhaled corticosteroids in COPD: systematic review and meta-analysis of randomised controlled trials and observational studies. Thorax. 2011;66(8): 699-708.

47. Lapi F, Kezouh A, Suissa S, Ernst P. The use of inhaled corticosteroids and the risk of adrenal insufficiency. Eur Respir J. 2013;42(1): 79-86.

48. Suissa S, Kezouh A, Ernst P. Inhaled corticosteroids and the risks of diabetes onset and progression. Am J Med. 2010;123(11):1001-1006.

49. Donaldson GC, Seemungal TA, Bhowmik A, Wedzicha JA. Relationship between exacerbation frequency and lung function decline in chronic obstructive pulmonary disease. Thorax. 2002;57(10):847-852.

50. Kanner RE, Anthonisen NR, Connett JE; Lung Health Study Research Group. Lower respiratory illnesses promote FEV(1) decline in current smokers but not ex-smokers with mild chronic obstructive pulmonary disease: results from the lung health study. Am J Respir Crit Care Med. 2001;164(3):358-364.

51. Connors AF Jr, Dawson NV, Thomas C, et al. Outcomes following acute exacerbation of severe chronic obstructive lung disease. The SUPPORT investigators (Study to Understand Prognoses and Preferences for Outcomes and Risks of Treatments). Am J Respir Crit Care Med. 1996; 154(4 Pt 1):959-967.

52. Festic E, Scanlon PD. Incident pneumonia and mortality in patients with chronic obstructive pulmonary disease. A double effect of inhaled corticosteroids? Am J Respir Crit Care Med. 2015;191(2):141-148.

53. Lipson DA, Barnhart F, Brealey N, et al. Once-daily single-inhaler triple versus dual therapy in patients with COPD. N Engl J Med. 2018; 378(18):1671-1680.

54. Papi A, Vestbo J, Fabbri L, et al. Extrafine inhaled triple therapy versus dual bronchodilator therapy in chronic obstructive pulmonary disease (TRIBUTE): a double-blind, parallel group, randomised controlled trial. Lancet. 2018;391(10125):1076-1084.

55. Lipworth BJ. Airway and systemic effects of inhaled corticosteroids in asthma: dose response relationship. Pulm Pharmacol. 1996;9(1): $19-27$. 
56. Kankaanranta H, Lahdensuo A, Moilanen E, Barnes PJ. Add-on therapy options in asthma not adequately controlled by inhaled corticosteroids: a comprehensive review. Respir Res. 2004;5:17.

57. Adams NP, Jones PW. The dose-response characteristics of inhaled corticosteroids when used to treat asthma: an overview of Cochrane systematic reviews. Respir Med. 2006;100(8):1297-1306.

58. Dahl R. Systemic side effects of inhaled corticosteroids in patients with asthma. Respir Med. 2006;100(8):1307-1317.

59. Price D, Yawn B, Brusselle G, Rossi A. Risk-to-benefit ratio of inhaled corticosteroids in patients with COPD. Prim Care Respir J. 2013;22(1): 92-100.

60. Sabroe I, Postma D, Heijink I, Dockrell DH. The yin and the yang of immunosuppression with inhaled corticosteroids. Thorax. 2013;68(12): 1085-1087.

61. Rodrigo GJ, Castro-Rodriguez JA, Plaza V. Safety and efficacy of combined long-acting beta-agonists and inhaled corticosteroids vs long-acting beta-agonists monotherapy for stable COPD: a systematic review. Chest. 2009;136(4):1029-1038.

62. Yawn BP, Li Y, Tian H, Zhang J, Arcona S, Kahler KH. Inhaled corticosteroid use in patients with chronic obstructive pulmonary disease and the risk of pneumonia: a retrospective claims data analysis. Int J Chron Obstruct Pulmon Dis. 2013;8:295-304.

63. Singh S, Loke YK. Risk of pneumonia associated with long-term use of inhaled corticosteroids in chronic obstructive pulmonary disease: a critical review and update. Curr Opin Pulm Med. 2010;16(2):118-122.

64. Magnussen H, Disse B, Rodriguez-Roisin R, et al. Withdrawal of inhaled glucocorticoids and exacerbations of COPD. $N$ Engl J Med. 2014;371(14):1285-1294.

65. Nadeem NJ, Taylor SJ, Eldridge SM. Withdrawal of inhaled corticosteroids in individuals with COPD - a systematic review and comment on trial methodology. Respir Res. 2011;12:107.

66. van der Valk P, Monninkhof E, van der Palen J, Zielhuis G, van Herwaarden C. Effect of discontinuation of inhaled corticosteroids in patients with chronic obstructive pulmonary disease: the COPE study. Am J Respir Crit Care Med. 2002;166(10):1358-1363.

67. Wouters EF, Postma DS, Fokkens B, et al. Withdrawal of fluticasone propionate from combined salmeterol/fluticasone treatment in patients with COPD causes immediate and sustained disease deterioration: a randomised controlled trial. Thorax. 2005;60(6):480-487.
68. Kunz LIZ, Postma DS, Klooster K, et al. Relapse in FEV1 decline after steroid withdrawal in COPD. Chest. 2015;148(2):389-396.

69. Suissa S, Rossi A. Weaning from inhaled corticosteroids in COPD: the evidence. Eur Respir J. 2015;46(5):1232-1235.

70. Watz H, Tetzlaff K, Wouters EF, et al. Blood eosinophil count and exacerbations in severe chronic obstructive pulmonary disease after withdrawal of inhaled corticosteroids: a post-hoc analysis of the WISDOM trial. Lancet Respir Med. 2016;4(5):390-398.

71. Cosio M, Baraldo S, Saetta M. Inhaled glucocorticoids and COPD exacerbations. N Engl J Med. 2015;372(1):92.

72. Yawn BP, Suissa S, Rossi A. Appropriate use of inhaled corticosteroids in COPD: the candidates for safe withdrawal. NPJ Prim Care Respir Med. 2016;26:16068.

73. Chapman KR, Hurst JR, Frent SM, et al. Long-term triple therapy de-escalation to indacaterol/glycopyrronium in patients with chronic obstructive pulmonary disease (SUNSET): a randomized, double-blind, triple-dummy clinical trial. Am J Respir Crit Care Med. 2018;198(3): 329-339.

74. Bafadhel M, Peterson S, De Blas MA, et al. Predictors of exacerbation risk and response to budesonide in patients with chronic obstructive pulmonary disease: a post-hoc analysis of three randomised trials. Lancet Respir Med. 2018;6(2):117-126.

75. Wedzicha JA, Banerji D, Chapman KR, et al. Indacaterol-glycopyrronium versus salmeterol-fluticasone for COPD. N Engl J Med. 2016;374(23) 2222-2234.

76. Crim C, Calverley PM, Anderson JA, et al. Pneumonia risk in COPD patients receiving inhaled corticosteroids alone or in combination: TORCH study results. Eur Respir J. 2009;34(3):641-647.

77. Sharafkhaneh A, Southard JG, Goldman M, Uryniak T, Martin UJ. Effect of budesonide/formoterol pMDI on COPD exacerbations: a double-blind, randomized study. Respir Med. 2012;106(2):257-268.

78. Singh D, Papi A, Corradi M, et al. Single inhaler triple therapy versus inhaled corticosteroid plus long-acting $\beta 2$-agonist therapy for chronic obstructive pulmonary disease (TRILOGY): a double-blind, parallel group, randomised controlled trial. Lancet. 2016;388(10048): 963-973.

79. Bassam M, Mayank V. Steroids in asthma: friend or foe. In: Qian X, editor. Glucocorticoids. New recognition of our familiar friend. IntechOpen; 2012:569-592.
International Journal of COPD

\section{Publish your work in this journal}

The International Journal of COPD is an international, peer-reviewed journal of therapeutics and pharmacology focusing on concise rapid reporting of clinical studies and reviews in COPD. Special focus is given to the pathophysiological processes underlying the disease, intervention programs, patient focused education, and self management protocols.

\section{Dovepress}

This journal is indexed on PubMed Central, MedLine and CAS. The manuscript management system is completely online and includes a very quick and fair peer-review system, which is all easy to use. Visit http://www.dovepress.com/testimonials.php to read real quotes from published authors. 